\title{
OS FEMINISMOS LATINO-AMERICANOS NOS ÚLTIMOS 50 ANOS: CONSIDERAÇÕES SOBRE UM ESTUDO
}

\begin{abstract}
AVELAR, Lúcia. BLAY, Eva Alterman (org.). 50 Anos de Feminismo Argentina, Brasil e Chile A Construção das Mulheres como Atores Políticos e Democráticos. São Paulo: Edusp, 2016, $352 \mathrm{p}$.
\end{abstract}

50 Anos de Feminismo Argentina, Brasil e Chile, livro organizado pelas professoras e pesquisadoras feministas Lúcia Avelar e Eva Alterman Blay, reúne uma série de trabalhos resultantes do projeto de pesquisa temático 50 Anos de Feminismo: Brasil, Argentina e Chile financiado pelo CNPq e que tem como objetivo comparar a evolução da condição de gênero nas últimas cinco décadas nesses países latinoamericanos que guardam em comum a passagem por ditaduras abruptas entre as décadas de 1960 e 1980, sendo o Brasil o caso mais icônico pela permanência sob o governo de generais durante mais de duas décadas, e a eleição de presidentas nos anos 200o: Dilma Rousseff, no Brasil; Cristina Kirchner, na Argentina; e Michele Bachelet, no Chile, que além de mulheres que conseguiram, com maior ou menor vantagem, vencer as barreiras masculinas e tradicionalistas do campo político, se situam no front progressista do espectro ideológico-partidário de suas respectivas nações. Os feminismos abordados no livro se referem ao movimento feminista contemporâneo, correspondente as segunda e terceira ondas na América Latina. Portanto, falar em 50 anos de Feminismo é necessariamente fazer uma segmentação do que tem significado uma tradição que remonta ao século XIX no continente, embora as lutas da primeira onda não fiquem de fora de alguns artigos que compõem a obra.

O livro é dividido em três partes, com dez artigos ao todo, sendo a primeira parte com quatro artigos e a segunda com seis artigos. A terceira, por se dedicar a estabelecer cronologias, possui seções e não trabalhos empíricos propriamente ditos. Todos eles de alguma forma buscam comparar dados relacionados à evolução de indicadores concernentes a categoria "sexo feminino" nos três países e demonstrar como temáticas caras ao movimento feminista tem adentrado o debate político e a política institucional propriamente dita. De maneira compartimentada, os trabalhos também guardam uma afinidade com a história dos feminismos argentino, brasileiro e chileno: plurais e polêmicos como são na reivindicação dos direitos das mulheres e nos impasses vividos que tem proporcionado uma adequação dos repertórios de ação do movimento feminista às especificidades que alcançam os contextos nacionais em cada período: como os processos de redemocratização nos países do Sul Global nos anos de 1980, a ascensão do projeto neoliberal e dos chamados ajustes estruturais nos anos de 1990 e a chegada de governos democrático-populares aos poderes centrais

Alberto Luis Silva

E-mail: albertosilvaterra@hotmail.com 
a partir de 1999, com a eleição de Hugo Chávez na Venezuela, que daria início a chamada era rosa na qual se incluem os países focalizados pela pesquisa liderada por Blay e Avelar, que curiosamente também são feministas históricas: estudiosas e espectadoras presentes em tempos de transformação.

A primeira parte se intitula 50 Anos de Feminismo: Uma Trajetória Histórica e foca exclusivamente na historicização dos casos. Esse é o ponto de partida para um livro em que quase todas as mãos realizadoras são mulheres, por vezes ativistas, como é previsível em coletâneas que tratam da temática do feminismo. O primeiro texto apresentado nesse momento, que é também o artigo que abre o trabalho após a apresentação das autoras, é uma pesquisa sobre as transformações sócio demográficas do Brasil e como as mulheres se inserem nelas, a partir de dados sobre ingresso no mercado de trabalho, escolarização básica, escolarização superior, mortalidade materna, óbitos por causas externas e distribuição por ocupações.

A visão dos quatro pesquisadores que assinam o texto (José Eustáquio Diniz Alves, Suzana Marta Cavenaghi, Angelita Alves de Carvalho e Maira Covre Sussai Soares) traz uma excelente reconstituição dos fatos que acompanham a melhora generalizada dos índices relativos a condição feminina e é otimista quanto a própria obtenção de prerrogativas e vantagens para a população de mulheres no país. Otimismo que tem origem na qualidade dos dados levantados e na evolução exponencial que eles apresentam em direção a um tipo ideal. Dois exemplos ocorrem nos já mencionados temas da "escolarização superior" e da "mortalidade materna". Enquanto essa passa por um declínio, que é positivo; aquela tem colocado as mulheres em vantagens em relação aos homens, gerando um processo de "desigualdade reversa".

Oprimeiroartigo ("Meio século de feminismo e o empoderamento das mulheres no contexto das transformações sociodemográficas do Brasil”) apontara que ainda há conquistas a serem realizadas, mas no geral prevalece a ideia - fundamentada quantitativamente - de que se caminha em direção a um progresso. A temática da mobilização social das mulheres brasileiras, das mais diversas cores, orientações sexuais, idades, classes sociais etc. pouco aparece aqui. Mas é importante mencionar que a trajetória do "empoderamento", em muito propiciada pela urbanização da nossa sociedade, está intimamente ligada aos altos e baixos do movimento feminista no país. O segundo trabalho ("Feminismos e direitos das mulheres na Argentina: história e situação atual”) se debruça sobre a Argentina, vizinho ao Brasil e ao Chile. Dora Barrancos e Nélido Archenti, autores do texto e pesquisadores argentinos, participam do projeto por meio de redes investigativas de cooperação internacional. Os autores rompem com o limite das cinco décadas e passam a contar a história do feminismo desde 1900, ainda quando as sufragistas saiam as ruas em vários países do mundo para exigir o direito ao voto feminino. O processo para que em 1947 o sufrágio fosse de fato "universal" e que em 1951 as mulheres participassem das eleições demandou negociações acirradas com atores políticos e a formação de associações entre mulheres com interesses comuns: feministas que percebiam a necessidade desde aquela época de rejeitar a ideologia maternalista, as exclusões 
arbitrárias de oportunidades significativas e uma série de formas de controle social impostas às mulheres argentinas.

Posteriormente a isso, é abordada também a ditadura de 1976 a 1983, marcada pelo terrorismo de Estado que impôs um influxo em alguns avanços dos anos 6o e 70 capitaneados de modo tímido pelo peronismo na figura de Eva -, a redemocratização do país, as reformas do Código Penal e a Lei de Cotas n. 24012 que inicia sua tramitação no final dos anos 8 o e é declarada lei de interesse público no ano de 2000. Importante destacar sobre esses pontos algumas questões: nesse interregno surge o Movimento das Mães da Praça de Maio, mulheres que sairam as ruas em 1977 de maneira ilegal para buscar respostas sobre o paradeiro de seus filhos: agenda que se somaria algum tempo mais tarde com a procura, por meio da associação de avós em busca de netos apropriados pelos repressores, de bebês que eram sequestrados de militantes presas/ os e entregues a famílias de oficiais'. Esse é um exemplo de mulheres não ligadas a partidos políticos e organizações de esquerda que tem perdurado no desejo por memória, verdade e justiça.

No que tange às leis penais, legislações que penalizam a discriminação de gênero, a violência de gênero e o feminicídio ou que permitem o reconhecimento da identidade de gênero e a integração das donas de casa aos sistemas de benefícios sociais tem se incorporado lentamente ao código constitucional dos argentinos. Já no que toca a Lei de Cotas, a Argentina talvez seja um dos exemplos mais proeminentes. Afinal, é no Parlamento desse país que se encontra a maior percentagem de mulheres proporcionalmente ao total na América Latina. As conquistas por inclusão feminina são resultantes também desse panorama de efusão das mulheres em um contexto democrático.

O terceiro artigo (“Como as mulheres se construíram como agentes políticas e democráticas: o caso brasileiro”) é da própria Eva Alterman Blay, que ao fazer o leitor presenciar novamente uma ruptura com o espaço delimitado dos cinquenta anos expresso pelo título e pelas propostas apresentadas ao início do livro, constrói uma história do feminismo no Brasil desde o século XIX. A luta das mulheres foi construída em várias fases que legitimaram as mulheres enquanto agentes/atrizes políticas e democráticas. Foi de uma luta por educação e alfabetização, restritas aos homens, a uma luta pelo sufrágio feminino que tornou o direito ao voto um item da Constituição de 1934 - promulgado em 1932 - e efetivado na práxis e de maneira obrigatória nas eleições de 1946. Antes mesmo de 32, em 1927 o direito ao voto foi efetivado localmente no Rio Grande do Norte de tal modo que a norte-rio-grandense Alzira Soriano foi eleita prefeita nessa época.

Na década de 30, a bióloga Bertha Luz, uma feminista icônica da época em que o termo "feminismo" não era frequente, chega a espaços de representação paralelamente a entrada da médica Carlota Pereira de Queiroz. São mulheres pioneiras em uma primeira metade do século XX em que jovens moças anarquistas e comunistas tomavam as ruas exigindo os seus direitos políticos e contestando as

1 A dinâmica do rapto de crianças para a adoção de famílias das classes média e alta associadas ao regime é belissimamente retratada no enredo do filme La Historia Oficial de Luis Puenzo de 1985 
idiossincracias da ordem instituída com um ideário revolucionário recém-chegado da Europa. As sufragistas também contavam com o apoio de mulheres da burguesia intelectualizada, particularmente da elite paulista, desde pelo menos o Império, tempo de Nísia Floresta e seu inaugural Direito das Mulheres e Injustiças dos Homens. Haveria desde então o que Blay chama de "o feliz casamento entre o feminismo e a política", talvez parafraseando "o infeliz casamento entre feminismo e o marxismo".

Os embates entre comunismo e movimento de mulheres, o papel do movimento feminista na ditadura brasileira e o ingresso das feministas no Estado fazem a sequência do texto que se dá em uma linearidade de recontagem dos potenciais e contradições das feministas brasileiras e seu engajamento nos espaços públicos. Um ponto alto desse artigo é a diferenciação entre "movimento de mulheres" e "movimento feminista". Essa nomenclatura é cercada de contradições, já que na década de 1970 há uma aproximação entre essas duas frentes de oposição ao regime autoritário instituído a revelia da soberania popular. $\mathrm{O}$ movimento de mulheres seria toda e qualquer mobilização, independente de filiação ideológica ou mesmo de uma postura autodeclarada política, que envolva a participação feminina em sua essencialidade organizativa. O movimento feminista abarcaria os dilemas referentes a igualdade de gênero e, por conseguinte a emancipação da mulher.

Embora o movimento de mulheres muitas vezes incorpore um caráter progressista, é preciso separar as manifestações das setoriais femininas dos movimentos revolucionários ou reformistas, dos sindicatos e das organizações de base que estiveram nos primeiros congressos de mulheres na abertura democrática, do feminismo militante que contestava os desmandos da ditadura, mas se mantinha atento a questões macro como a causa do aborto, a revogação do Estatuto da Mulher Casada, a derrocada do pátrio poder e o combate as violações contra as mulheres como o estupro e as agressões domésticas. O Ano Internacional da Mulher em 1975 é um parâmetro importante para o movimento feminista brasileiro contemporâneo, dada a atuação dos feminismos militantes nas chamadas delegações internacionais, e a entrada da questão feminina no ideário das grandes discussões da globalização liberal.

O último texto da primeira parte ("50 anos de Feminismo no Chile: texto e contexto”), de autoria da pesquisadora, antropóloga e militante chilena Eliana Largo, faz o mesmo trabalho historiográfico realizado em relação a Argentina e o Brasil, só que dessa vez em relação ao Chile. A trajetória tem semelhanças fundamentais, o que certamente fortaleceu o critério de escolha dos casos pelas pesquisadoras. Há um primeiro momento em que o sufrágio feminino é o grande objetivo. A conquista do direito ao voto fez das reivindicações políticas das feministas algo relativamente apaziguado já que a participação das mulheres recebeu permissão para acontecer nas décadas de 1950 e 1960. Isso, entretanto, não impediu um fortalecimento da mobilização na segunda metade dos anos 6o, já que a questão feminina ganha entrada nos governos eleitos democraticamente, principalmente no de Salvador Allende, socialista democraticamente eleito em 1970 que deu cabo a um conjunto de reformas no Chile, dentre elas a criação de uma pasta para as mulheres e o fomento às Casas de 
Mães e os Comitês de Donas de Casa que fortaleciam a prática das assembleias entre as mulheres. É a época da ilusão da integração - termo de Edda Gaviola, Eliana Largo e Sandra Palestro, historiadoras chilenas - das mulheres à excludente sociedade chilena.

Os avanços aparentes, mas importantes, são interrompidos com o golpe de 1973, movimento similar ao ocorrido nos demais países que sucumbiram ao autoritarismo patrocinado pelos EUA. Centros de estudo e grupos de reflexão na clandestinidade bem como mobilizações tímidas nos anos 8o marcam a resistência das feministas a mais sangrenta ditadura da região. Com o slogan "Democracia no país e em casa”, as mulheres reivindicaram a abertura democrática no Chile que veio a ocorrer a partir do plebiscito de 1988, convocado pelo governo de Pinochet, em que a vitória do "Não" referente a não continuidade da ditadura saiu vitoriosa das urnas em um processo fortemente controlado pelo governo.

As desigualdades estruturais impostas por um modelo patriarcal, com todas as controvérsias desse conceito, e a permanência de uma série de entraves referentes aos próprios atrasos sociais que permeiam o perfil da população são destacados por Eliana Largo como fatores que ainda impossibilitam avanços substanciais em questões como a legalização do aborto, por exemplo, já que o Chile possui uma das legislações mais restritivas do mundo na matéria. De tal modo que a parcela feminista da sociedade civil chilena no século XXI continua a lidar com repetidos desafios.

Na atualidade, os principais campos de ação/reflexão/intervenção em que se destacam os coletivos feministas, organizações não governamentais, observatórios e redes nacionais em relação à autonomia das mulheres - autonomia dos corpos -, de um enfoque crítico do desenvolvimento - "gênero do desenvolvimento" - e de uma óptica de direitos humanos, são as violências física, sexual e psicológica: os chamados direitos sexuais e reprodutivos; a participação política e a participação econômica. Campos que implicam o direito a decidir, a optar e a criar o que não existe.

A segunda parte do livro intitulada Velhos e Novos Desafios do Feminismo se volta para algumas questões para as quais os movimentos feministas argentino, brasileiro e chileno tem se voltado - deixando de lado os enquadramentos históricos da primeira parte, a força-motriz do livro e seu destaque - a partir de alguns trabalhos sob contextos específicos como o primeiro que remonta a organização das mulheres que trabalham em cooperativas sociais de reciclagem, principalmente no estado de Paraná, onde as catadoras tem promovido encontros anuais nos últimos anos para debater as articulações políticas pela inserção no mercado de trabalho, o cooperativismo, a responsabilidade social apregoada por seus princípios fundantes entre outras questões como a distribuição e reciclagem do lixo de modo geral. O segundo texto ("Coalizões queer: aborto, feminismo e dissidências sexuais de 1990 a 2005 em Buenos Aires") discorre sobre as dissidências sexuais e o dilema do aborto 
entre 1990 e 2005 no movimento feminista argentino. Mabel Belucci, autora, reaviva alguns pressupostos da teoria queer que influenciaram os novos feminismos e oferece ao leitor alguns passos da retórica radical e anticapitalista de correntes do feminismo argentino e explica como tem se dado a campanha pelo aborto legal, seguro e gratuito no país, que não avançou mesmo sob os idos do kirchnerismo.

$\mathrm{O}$ quarto texto ("A cidadania imaginada pelas mulheres afro-brasileiras: da ditadura militar à democracia”), de Flávia Rios, se volta para uma categoria de mulheres que está na base da pirâmide social brasileira, sendo consistentemente marginalizadas por um modelo de dominação de classe, raça e gênero: as mulheres negras. Começando pela referência ao clássico de Carolina Maria de Jesus Quarto de Despejo, o texto percorre as referências políticas e culturais que tanto na ditadura quanto na democracia tem relegado as mulheres negras ao lugar do "outro" em nossa sociedade. Para ter uma noção dos modos de compreensão da problemática da mulher negra, que contesta a noção de um universal feminino em sua auto representação contra hegemônica, Rios recorre ao conceito de interseccionalidade que contém em si a noção analítica das desigualdades sobrepostas em contraposição a ideia minimalista e operacional de intersetorialidade.

Já o quinto texto ("Como as mulheres se representam na política? Os casos de Argentina e Brasil”) da segunda parte é uma realização de Lúcia Avelar em parceria com a pesquisadora Patrícia Rangel. O grande objetivo aqui é a partir do debate sobre representação política, próprio do mainstream da ciência política, comparar a maneira como se opõe o déficit de representação feminina das brasileiras em relação ao "superávit" da representação feminina nas argentina. Para isso, as estudiosas dão ênfase além de números a conceitos como "oportunidades políticas" de Sidney Tarrow e "representação extraparlamentar" pensado por cientistas políticos e cientistas políticas como David Plotke e Jane Mansbridge. O sexto e último artigo da segunda parte fala sobre como a questão do aborto foi enquadrada na disputa eleitoral presidencial brasileira de 2010, na qual ganhou centralidade em meio ao embate entre José Serra e Dilma Rousseff e as tensões envolvendo a retórica neopetenconstal e conservadora que objetivava formar consenso contra uma pauta benéfica as mulheres.

A terceira parte do livro se intitula Breves Cronologias do Movimento Feminista e fecha a obra mostrando de maneira esquemática as evoluções em cada um dos estudos significativos esboçados sob a organização da pesquisadora do CESOP/ UNICAMP Lúcia Avelar e da professora sênior da Universidade de São Paulo Eva Blay. Importante ressaltar que esse trabalho exemplar é resultado de uma longa pesquisa que permitiu um intercâmbio internacional significativo entre investigadoras e veio a público nesse livro publicado pela Editora da USP no ano de 2016. Sem dúvidas o texto, em seu conjunto compartimentalizado de artigos, contribui para esclarecer os limiares de como os movimentos feministas latino-americanos, resguardadas

2 O terceiro texto ("Feminismo no Chile: traços de ontem e hoje"), não detalhado aqui, aborda de maneira breve argumentos a respeito do feminismo chileno que já estavam no último texto da primeira parte. 
as especificidades dos Estados-nação, tem se comportado ao longo dos anos, especialmente nos difíceis anos das ditaduras civil-militares e no processo, por vezes dito pelos analistas incompleto, de redemocratização em cada país. As pesquisadoras com suas respectivas perguntas nos levam a refletir sobre os impasses que permitiram conquistas importantes, mas que continuam a atravancar o debate necessário de questões urgentes, onde o que está em jogo não é mais a inclusão, mas a qualidade e a igualdade dessa inclusão, bem como a própria vida das mulheres. 